\title{
Recolhimento da taxa de mandato judicial
}

Conselho Nacional de Justiça (CNJ)

\section{PEDIDO DE PROVIDÊNCIAS - CONSELHEIRO 0003030-}

\subsection{0}

Requerente: Alberto Barduco

Requerido: Tribunal de Justiça do Estado de São Paulo

Advogado(s): SP078015 - Alberto Barduco (REQUERENTE)

PEDIDO DE PROVIDÊNCIAS. TAXA DE MANDATO JUDICIAL. EXAME DE CONSTITUCIONALIDADE DE LEI ESTADUAL. INCOMPETÊNCIA DO CNJ. NATUREZA JURISDICIONAL DA MATÉRIA. IMPUGNAÇÃO POR MEIO DE RECURSOS PRÓPRIOS. IMPACTO NA CELERIDADE E NA EFICIÊNCIA DO JUDICIÁRIO ESTADUAL. NECESSIDADE DE APERFEIÇOAMENTO DA NORMA.

1. Não compete ao $\mathrm{CNJ}$ o exame da constitucionalidade de lei, por se tratar de ato oriundo do Poder Legislativo, estranho, portanto, à sua atribuição precípua de controle da atuação administrativa e financeira do Poder Judiciário.

2. As decisões que determinam o recolhimento da "taxa de mandato judicial" são proferidas no bojo de processos judiciais, pelo que são atacáveis por recurso próprio. Logo, não são alcançadas pelo controle administrativo exercido por este Conselho. 
3. Não obstante, no intuito de buscar o aperfeiçoamento e a eficiência dos serviços judiciários, recomenda-se ao TJSP a adoção de providências e/ou a apresentação ao órgão responsável de proposta com vistas à alteração/extinção da referida "taxa".

4. Pedido de Providências parcialmente procedente.

\section{Relatório}

Trata-se de Pedido de Providências apresentado pelo advogado ALBERTO BARDUCO, por meio do qual requer que este Conselho determine ao TRIBUNAL DE JUSTIÇA DO ESTADO DE SÃO PAULO que se abstenha de "exigir dos advogados, por ocasião da juntada de procurações, o recolhimento da 'taxa de procuração', devendo, para tanto, comunicar aos juízes de todas as Comarcas do Estado de São Paulo de que tal exigência não encontra amparo na Constituição Federal, sem prejuízo da validade da cobrança dessa taxa junto aos advogados que integram a Carteira de Previdência dos Advogados de São Paulo (segurados)".

2. Alega, em síntese, que:

a) com a juntada do instrumento de mandato, os advogados atuantes naquele Estado muitas vezes são compelidos a recolher a "taxa do mandato judicial", comumente denominada "taxa de procuração", prevista na Lei paulista n. 10.394, de 16 de dezembro de 1970, que reorganiza a Carteira de Previdência dos Advogados de São Paulo;

b) tem se recusado a recolher a referida "taxa", protocolizando petição nos autos, "sendo que a grande maioria dos juízes tem silenciado sobre o assunto, ou seja, não insiste na necessidade de tal recolhimento, ao passo que alguns poucos mandam oficiar o IPESP (Instituto de Previdência do Estado de São Paulo) a cerca (sic) do não recolhimento, enquanto que um ou outro mandou oficiar a ORDEM DOS ADVOGADOS DO BRASIL que, por sua vez, declina de qualquer providência de natureza administrativa ou disciplinar, de vez que a $O A B$ não possui nenhuma ingerência sobre os destinos dessa 'taxa'";

c) os valores recolhidos sob tal rubrica têm "como objetivo a seguridade complementar do advogado, no caso, do advogado inscrito na Carteira de Previdência dos Advogados de São Paulo", administrada pelo Instituto de Previdência do Estado de São Paulo - IPESP;

d) com o advento da Lei n. 13.549, de 26 de maio de 2009, a citada Carteira de Previdência foi colocada em regime de extinção; 
e) a "taxa de procuração" não é custa processual, não se admitindo que o juiz determine o recolhimento de valores não previstos na Lei de Custas do Estado de São Paulo (Lei n. 11.608, de 29 de dezembro de 2003); e

f) a determinação de recolhimento da "taxa" fere o artigo 98, §2으, da Constituição Federal, na medida em que se destina a entidade particular e não às atividades específicas da Justiça.

3. O eminente Conselheiro Lúcio Munhoz, que me antecedeu, solicitou informações ao TJSP (DESP22).

4. Devidamente intimado, o TJSP, por intermédio da Corregedoria-Geral da Justiça, destacou:

\section{(...)}

Tal contribuição é devida pelo outorgante do mandato; sendo exigida a fiscalização de seu recolhimento pelo servidor do judiciário, quando da juntada aos autos do mandato (...). (grifo inexistente no original)

2. Muitos questionam a constitucionalidade de tal contribuição, ante os arts. 40 e 98, §2º da Constituição Federal.

Em relação ao primeiro dispositivo legal, a inconstitucionalidade derivaria do fato da lei exigir contribuição para manutenção de carteira previdenciária de advogados, ou seja, profissionais liberais, que não são servidores públicos (servidores titulares de cargos efetivos), ao contrário do que preconiza o art. 40 da CF.

Já em relação ao art. 98, §2, que foi inserido pela Emenda 45, tal dispositivo deixa claro que as custas e emolumentos exigidos devem se destinar exclusivamente ao custeio das atividades específicas da Justiça.

Contudo, salvo melhor juízo, não compete à Corregedoria Geral da Justiça decidir sobre a constitucionalidade da lei estadual que instituiu tal contribuição.

3. Já em relação ao outro argumento, qual seja, a extinção do IPESP e da carteira, ele está prejudicado.

Isto porque apesar da lei complementar estadual n-1.010/2007 ter determinado a extinção do IPESP e da carteira, em seu art. 40, §1ㅜㅇ foi editada outra lei, de no 13.549, em 26/05/2009, que em seu art. 34 revogou o anterior art. 40, §1으, restabelecendo a situação.

Aliás, nesta última lei foi determinado o regime de extinção da carteira, tendo sido mantida a contribuição decorrente do mandato judicial como receita da carteira (cf. art. 18, II da lei estadual 13549/2009). (INF23, DOC24) 
5. Em razão das informações prestadas pelo TJSP, o requerente registrou que "não está questionando a validade dessas leis estaduais (...), mas sim a descabida e ilegal cobrança que o Tribunal de Justiça de São Paulo faz, através dos seus I. Juízes, ao exigir, quando da juntada aos autos de instrumento de mantado, o recolhimento de uma 'taxa de procuração', que não é nem taxa, nem contribuição, e muito menos imposto, de vez que não tem como fato gerador a prestação de serviços públicos de natureza forense, de modo que, como dito na inicial, contrapõe-se ao que dispõe o art. 98, §2º da Constituição Federal". (REQAVU25)

6. Em petição complementar, o Tribunal requerido anotou que:

(...) o recolhimento da contribuição se faz por determinação legal. Não pode o Judiciário dispensar, contra a lei, o pagamento e nem pode, ainda que a irregularidade da contribuição fosse aceita (e não há aceitação desse ponto), dar início a eventual ação direta de inconstitucionalidade. E, como o Judiciário nem sequer se beneficia com o recolhimento, falta até o requisito de interesse de agir para questionar de forma incidental a pertinência da norma ao sistema.

Destarte, no âmbito desta Corregedoria, já se assentou que não há providência passível de ser adotada. (INF26)

\section{É o Relatório.}

\section{Voto}

7. Conforme relatado, o requerente pretende por meio do presente Pedido de Providências que este Conselho determine ao TJSP que se abstenha de exigir o recolhimento da "taxa de mandato judicial" prevista na Lei paulista n. 10.394, de 16 de dezembro de 1970, e que, para tanto, comunique os juízes de que tal exigência não encontra amparo na Constituição.

8. A referida "taxa" é, na verdade, uma contribuição devida pelo outorgante do mandato judicial como condição para juntada aos autos de instrumento de procuração ou de substabelecimento.

9. Para melhor compreensão do tema, vale traçar o histórico dessa contribuição.

10. A Lei Estadual n. 5.174, de 7 de janeiro de 1959, que dispôs sobre a criação, no Instituto de Previdência do Estado de São Paulo, da "Carteira de Previdência dos Advogados de São Paulo", estabeleceu em seu artigo 16, incisos V e VI: 
Artigo $16^{o}-$ A receita da Carteira de Previdência dos Advogados de São Paulo será constituída:

(...)

$V$ - da taxa fixa de Cr\$100,00 (cem cruzeiros), cobrada, a título de contribuição individual do mandante, sobre todo instrumento de mandato judicial oferecido ou produzido em juízo;

VI - da taxa fixa de Cr\$100,00 (cem cruzeiros) cobrada sobre qualquer substabelecimento nas condições do inciso anterior

11. Com a edição da Lei Estadual n. 10.394, de 16 de dezembro de 1970, que reorganizou a Carteira de Previdência dos Advogados de São Paulo e revogou o regramento anterior, bem como da Lei n. 13.549, de 26 de maio de 2009, que declarou em regime de extinção a referida Carteira, o legislador optou por manter a contribuição a cargo do outorgante de mandato judicial como uma das fontes de receita, a teor dos artigos 40, inciso III, e 18, inciso II, respectivamente.

12. Fundados nessa previsão legal, por ocasião da juntada de instrumentos de procuração, magistrados paulistas proferem despacho nos autos determinando que a parte autora promova o recolhimento da "taxa de procuração". 13. Cumpre destacar, por outro lado, a teor dos documentos acostados pelo requerente (DOC9 e DOC10), que o impulso ao processo tem sido condicionado ao recolhimento da referida "taxa", o que parece conferir à referida contribuição natureza de custa processual. Daí porque, de acordo com o requerente, haveria afronta ao que dispõe o artigo 98 , $§ 2^{2}$, da Constituição Federal, na medida em que os valores arrecadados são destinados à Carteira de Previdência dos Advogados e não ao custeio de atos forenses ou processuais.

14. Recorde-se a disposição constitucional:

Art. 98. A União, no Distrito Federal e nos Territórios, e os Estados criarão:

(...)

\$2․ As custas e emolumentos serão destinados exclusivamente ao custeio dos serviços afetos às atividades específicas da Justiça.

15. Ocorre que o exame da constitucionalidade de leis não se insere dentre as competências constitucionais do $\mathrm{CNJ}$, ainda que destinadas ao Judiciário, por se tratar de ato oriundo do Poder Legislativo, estranho, portanto, à sua 
atribuição precípua de controle da atuação administrativa e financeira do Poder Judiciário. Nesse sentido já se posicionou o STF e o próprio CNJ:

O CNJ, embora seja órgão do Poder Judiciário, nos termos do art. 103-B, §4º, II, da CF, possui, tão somente, atribuições de natureza administrativa e, nesse sentido, não the é permitido apreciar a constitucionalidade dos atos administrativos, mas somente sua legalidade. (MS n. 28.872-AgR, Rel. Min. Ricardo Lewandowski, julgamento em 24-2-2011, Plenário, DJE de 18-3-2011.)

CONCURSO PÚBLICO. SERVENTIA EXTRAJUDICIAL. INTERESSE MERAMENTE INDIVIDUAL.

- "O CNJ não tem competência para declarar a constitucionalidade ou inconstitucionalidade de lei ou ato normativo federal ou estadual, porque ato estranho à sua natureza de órgão controlador da atividade administrativa e financeira do Poder Judiciário" (PP 5866).

- Não se conhece de pedido de natureza meramente individual, independentemente do direito subjetivo, que deve ser submetido à apreciação jurisdicional (Precedentes do CNJ: PCA 197, PP 9867 e PCA 573).

- Sobrestamento do procedimento, até que o STF decida a ADI 2.168 sobre a constitucionalidade de lei estadual que estabelece requisitos para a inscrição em concurso para serventias extrajudiciais. (PCA n. 0001245-95.2008.2.00.0000, Rel. Cons. Paulo Lôbo, j. 21.10.2008).

\section{PROCEDIMENTO DE CONTROLE ADMINISTRATIVO.}

1. (....)

2. (...)

3. DO PROVIMENTO DE CARGOS EM COMISSÃO DESTINADOS A GABINETES DE DESEMBARGADORES AINDA NÃO EMPOSSADOS - LEI COMPLEMENTAR ESTADUAL NNo 162, DE 18 DE MAIO DE 2010 - RORAIMA. Questão relativa à inaplicabilidade ou inconstitucionalidade de Lei Estadual. Incompetência do CNJ para apreciar a matéria, nos termos do art. 103-B, $\S \S 4^{\circ}$ e 5º da Constituição da República.

4. (...)

(PCA n. 0002432-36.2011.2.00.0000, Rel. Cons. Carlos Alberto Reis de Paula, j. 27.9.2011) 
16. Insta destacar que o STF julgou duas Ações Diretas de Inconstitucionalidade (ADI n. 4.291/SP e ADI n. 4.429/SP) em face da Lei n. 13.549, de 26 de maio de 2009, que declarou em regime de extinção a Carteira de Previdência dos Advogados de São Paulo.

17. Todavia, a declaração de inconstitucionalidade de alguns dispositivos e a interpretação conforme a Constituição conferida a outros não tocaram especificamente no tema ora posto à apreciação do CNJ (taxa de procuração). Senão vejamos:

ESTADO - RESPONSABILIDADE - QUEBRA DA CONFIANÇA. A quebra da confiança sinalizada pelo Estado, ao criar, mediante lei, carteira previdenciária, vindo a administrá-la, gera a respectiva responsabilidade.

$$
\text { A CÓ R D ÂO }
$$

Vistos, relatados e discutidos estes autos, acordam os Ministros do Supremo Tribunal Federal em julgar parcialmente procedente a ação direta para declarar a inconstitucionalidade dos $\S 2^{o}$ e $\$ 3^{\circ}$ do artigo $2^{o}$ da Lei $n^{\circ}$ 13.549, de 2009, do Estado de São Paulo, no que excluem a assunção de responsabilidade pelo Estado, e conferir interpretação conforme à Constituição ao restante da norma impugnada, proclamando que as regras não se aplicam a quem, na data da publicação da Lei, já estava em gozo de benefício ou já tinha cumprido, com base no regime instituído pela Lei no 10.394, de 1970, os requisitos necessários à concessão, nos termos do voto do relator, em sessão presidida pelo Ministro Cezar Peluso, na conformidade da ata do julgamento e das respectivas notas taquigráficas." (STF - ADI n. 4.291/SP e ADI n. 4.429/SP, Rel. Min. Marco Aurélio, julgamento em 14.12.2011, Plenário, DJe de 9.3.2012 e 14.3.2012, respectivamente) (grifo inexistente no original)

18. Por outro lado, as decisões que determinam o recolhimento da referida "taxa" são proferidas no bojo de processos judiciais, pelo que são atacáveis por recurso judicial próprio. Assim, em se tratando de ato judicial, não são alcançadas pelo controle administrativo exercido por este Conselho.

19. Assim, ante o conteúdo e a natureza jurisdicional, não compete ao CNJ, na sua missão constitucional precípua de controle da atuação administrativa e financeira do Poder Judiciário, se imiscuir nesse âmbito de atuação. Nesse sentido: 
CONSELHO NACIONAL DE JUSTIÇA. PEDIDO DE PROVIDÊNCIAS PARA REVOGAR DECISÃO ACERCA DE HONORÁRIOS ADVOCATÍCIOS E DE APLICAÇÃO DE SANÇÃO DISCIPLINAR. NATUREZA JURISDICIONAL. INCOMPETÊNCIA DO CNJ. NÃO CONHECIMENTO.

O CNJ, em princípio, não tem competência para apreciar decisão que, em qualquer fase do processo de execução, disponha acerca da validade de contrato de honorários. Esse gênero de decisão possui natureza jurisdicional, e, certa ou errada, justa ou injusta, deve ser impugnada por meio dos recursos apropriados. Somente se constatada infração disciplinar - não vislumbrada no caso poderá o magistrado responder em razão de ato judicial. Pedido de providências não conhecido. (PP n. 0004690-19.2011.2.00.0000, Relator p/acórdão Cons. Wellington Cabral Saraiva, j. 4.7.2012)

PROCEDIMENTO DE CONTROLE ADMINISTRATIVO. MATÉRIA SUB JUDICE. - "Inarredável a competência deste Conselho para controle da atuação administrativa do Poder Judiciário, nos termos do parágrafo $4^{\circ}$ do artigo 103-B da Constituição Federal, mas não deve o CNJ avançar no debate de sorte a atingir eventual decisão judicial, ou nela intervir, por razão de segurança jurídica e respeito à função jurisdicional, evitando-se possíveis pronunciamentos conflitantes. (CNJ - PCA 631-Rel. Cons. Altino Pedrozo

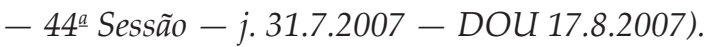

Pedido de Providências. Decisão judicial. Revisão. Competência do Conselho Nacional de Justiça. Controle do ato jurisdicional somente mediante recursos judiciais previstos na Constituição e nas leis processuais. Competência do Conselho Nacional de Justiça restrita ao controle da atuação administrativa e financeira do Poder Judiciário e cumprimento dos deveres funcionais dos magistrados. Tripartição e independência dos poderes (CF, arts. $2^{\circ}$ e 103-B, $\$ 4^{\circ}$ ).

I - Não cabe ao Conselho Nacional de Justiça realizar controle ou rever atos jurisdicionais dos órgãos do Poder Judiciário.

II - Revisão de decisão judicial só é passível mediante interposição dos recursos previstos na Constituição Federal e nas leis processuais.

III - Ao Conselho Nacional de Justiça, órgão de controle do Judiciário, só compete examinar a atuação administrativa e financeira dos órgãos do Poder Judiciário e o cumprimento dos deveres funcionais dos magistrados (CF, art. $\left.103-B, \S 4^{\circ}\right)$. 
IV - Em face da adoção do princípio da Tripartição dos Poderes, e sua independência, incabível controle da decisão judicial pelos demais Poderes (CF, art. $\left.2^{\circ}\right)$.

$V$ - Pedido de Revisão de decisão judicial não conhecido, por incabível.

(PP 21 - Rel. Cons. Jirair Meguerian - 3a Sessão - j. 16.8.2005 - DJU de 5.9.2005).

20. Não obstante, impende registrar que o recolhimento de tal contribuição está a cargo das secretarias das unidades judiciárias, podendo o serventuário da Justiça, inclusive, ser responsabilizado pelo pagamento da contribuição não arrecadada, a teor do artigo 50 da Lei Estadual 10.394/70:

Artigo 48 - Para o instrumento de mandato judicial ser anexado ao processo, deverá ser paga uma contribuição, por mandante, de 1,5\% sobre o salário mínimo vigente na Capital do Estado, arredondando-se para mais a fração de cruzeiro.

(...)

Artigo 49 - O beneficiário de justiça gratuita está dispensado do pagamento a que se refere o artigo anterior, mas, vencedor na causa, a contribuição será cobrada ao vencido, na proporção em que o for, devendo ser incluída, pelo contador, na conta de liquidação.

Artigo 50 - O servidor da Justiça que desatender ao disposto nos artigos 48 e 49 será responsável pelo pagamento da contribuição não arrecadada e sujeito a multa do triplo do total, cobrável executivamente.

21. Diante dessa atribuição extra sobre os "ombros" de magistrados e serventuários da justiça paulista e haja vista a demonstração de que o andamento do processo fica condicionado à prévia comprovação de tal recolhimento, parece evidente que o cumprimento dessa discutível previsão legal vem, há anos, gerando impactos diretos na celeridade e na eficiência do judiciário estadual. 22. Vale recordar, a propósito, a finalidade ou a razão de ser do Pedido de Providências no âmbito do CNJ, assim "conceituada" no artigo 98 do Regimento Interno:

Art. 98. As propostas e sugestões tendentes à melhoria da eficiência e eficácia do Poder Judiciário bem como todo e qualquer expediente que não tenha classificação específica nem seja acessório ou incidente serão incluídos 
na classe de pedido de providências, cabendo ao Plenário do CNJ ou ao Corregedor Nacional de Justiça, conforme a respectiva competência, o seu conhecimento e julgamento.

23. Desnecessário relembrar que esse dispositivo regimental deve ser lido à luz da competência constitucional conferida ao CNJ para "recomendar providências" e "zelar pela observância do artigo 37", notadamente dos princípios da legalidade, impessoalidade, moralidade, publicidade e eficiência.

24. Assim, no intuito de buscar o aperfeiçoamento e a eficiência dos serviços judiciários, impõe-se recomendar ao TJSP que adote providências e/ou apresente ao órgão responsável proposta com vistas à alteração/extinção da referida "taxa de procuração".

25. Se é correto que não pode o TJSP dispensar um pagamento previsto em lei e nem dar início a eventual ação direta de inconstitucionalidade, também é certo que deve zelar pelo bom funcionamento das suas unidades judiciárias e, nesse sentido, buscar desincumbir-se de todo e qualquer procedimento que possa sobrecarregar magistrados e servidores e impactar a sua celeridade e eficiência, notadamente em proveito de instituições estranhas ao Judiciário. 26. Pelas razões expostas, julgo procedente em parte o pedido a fim de recomendar ao TJSP que adote providências e/ou apresente ao órgão responsável proposta com vistas à alteração ou extinção da "taxa de procuração". 27. Encaminhe-se cópia desta decisão ao Procurador-Geral de Justiça do Estado de São Paulo, para ciência e adoção das medidas que entender pertinentes, servindo o presente como ofício.

À Secretaria Processual para as providências devidas.

É como voto.

\section{RUBENS CURADO SILVEIRA \\ Conselheiro}

Esse Documento foi Assinado Eletronicamente por RUBENS CURADO

SILVEIRA em 24 de Fevereiro de 2014 às 17:42:52

O Original deste Documento pode ser consultado no site do E-CNJ.

Hash: 57e951e079629248d10e2c7d56cd2827 